\title{
Subsecond Regulation of Synaptically Released Dopamine by COMT in the Olfactory Bulb
}

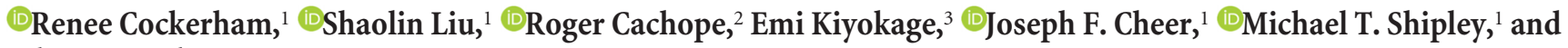 \\ Adam C. Puche ${ }^{1}$ \\ ${ }^{1}$ University of Maryland School of Medicine, Baltimore, Maryland 21201, ${ }^{2}$ CHDI Foundation/CHDI Management, New York, New York 10001 , and \\ ${ }^{3}$ Kawasaki Medical School, Matsushima, Kurashiki-City, Okayama
}

The efficacy of neurotransmission depends on multiple factors, including presynaptic vesicular release of transmitter, postsynaptic receptor populations and clearance/inactivation of the transmitter. In the olfactory bulb (OB), short axon cells (SACs) form an interglomerular circuit that uses GABA and dopamine (DA) as cotransmitters. Selective optical activation of SACs causes GABA and DA corelease, resulting in a fast, postsynaptic GABA inhibitory response and a slower G-protein-coupled DA rebound excitation. In most systems, vesicular release of DA is cleared by the dopamine transporter (DAT). However, in the 0B, high levels of specific DA metabolites suggest that enzymatic catalysis by catechol-O-methyl-transferase (COMT) predominates over DAT re-uptake. To assess this possibility we measured the amount of the DA breakdown enzyme, COMT, present in the OB. Compared with the striatum, the brain structure richest in DA terminals, the OB contains 50\% more COMT per unit of tissue. Furthermore, the OB has dramatically less DAT compared with striatum, supporting the idea that COMT enzymatic breakdown, rather than DAT recycling, is the predominant mechanism for DA clearance. To functionally assess COMT inactivation of vesicular release of DA we used fast-scan cyclic voltammetry and pharmacological blockade of COMT. In mice expressing ChR2 in tyrosine hydroxylase-containing neurons, optical activation of SACs evoked robust DA release in the glomerular layer. The COMT inhibitor, tolcapone, increased the DA signal 2-fold, whereas the DAT inhibitor GBR12909 had no effect. Together, these data indicate that the OB preferentially employs COMT enzymatic inactivation of vesicular release of DA.

Key words: COMT; dopamine; enzymatic; olfactory; transporter; voltammetry

Significance Statement

In the olfactory bulb (OB), odors are encoded by glomerular activation patterns. Dopaminergic short axon neurons (SACs) form an extensive network of lateral connections that mediate cross talk among glomeruli, releasing GABA and DA onto sensory nerve terminals and postsynaptic neurons. $\mathrm{DA}$ neurons are $\sim 10$-fold more numerous in $\mathrm{OB}$ than in ventral tegmental areas that innervate the striatum. We show that $\mathrm{OB}$ has abundant expression of the $\mathrm{DA}$ catalytic enzyme catechol- 0 -methyl-transferase (COMT), but negligible expression of the dopamine transporter. Using optogenetics and fast-scan cyclic voltammetry, we show that inhibition of COMT increases DA signals $\sim 2$-fold. Thus, in contrast to the striatum, which has the brain's highest proportion of DAergic synapses, the DA catalytic pathway involving COMT predominates over re-uptake in OB.

\section{Introduction}

Activated neurons release neurotransmitters, which must be rapidly and efficiently cleared from synaptic and extrasynaptic com-

Received Feb. 29, 2016; revised May 25, 2016; accepted June 9, 2016.

Author contributions: J.F.C., M.T.S., and A.C.P. designed research; R. Cockerham, S.L., R. Cachope, and E.K. performed research; R. Cockerham, S.L., R. Cachope, E.K., J.F.C., and A.C.P. analyzed data; M.T.S. and A.C.P. wrote the paper.

This work was supported by NIH Grants DC010915 and DC005676.

The authors declare no competing financial interests.

Correspondence should be addressed to Dr. Adam C. Puche, Department of Anatomy and Neurobiology, University of Maryland School of Medicine, 20 Penn Street, Room 251, Baltimore, MD 21201. E-mail: apuche@som.umaryland.edu.

DOI:10.1523/JNEUROSCI.0658-16.2016

Copyright (C) 2016 the authors $\quad 0270-6474 / 16 / 367779-07 \$ 15.00 / 0$ partments to terminate transmission. The dynamics of clearance shape the amplitude and duration of postsynaptic responses. Brain regions differ in transmitter clearance mechanisms. The two most common examples are re-uptake by specific transporters, eg, dopamine (DA) reuptake via the dopamine transporter (DAT), 5HT via serotonin transporters (SERT; also knows as 5-HTT), or via enzymatic breakdown, eg, acetylcholine degradation via acetylcholine esterase (AChE).

Dopamine, a major transmitter in midbrain-striatal-cortical and olfactory bulb circuits, can be cleared by reuptake or enzymatic degradation. Reuptake is through the DAT, located within the membrane of dopaminergic neurons (Hersch et al., 1997). DAT uses the driving force of the ion concentration gradient provided by $\mathrm{Na}^{+} / \mathrm{K}^{+}$ATPase to transport $2 \mathrm{Na}^{+}$ions, $1 \mathrm{Cl}-$ ion, 
and DA back into the synapse. DAT-recovered DA may be recycled into synaptic vesicles or broken down by monoamine oxidase (MAO) to DOPAC (3,4-dihydroxyphenylacetic acid). Drugs of abuse, such as cocaine or amphetamine, decrease DAT function and cause excess DA at the synapse (Sesack and Grace, 2010).

Released DA can also be broken down by the enzyme catechol$O$-methyl-transferase (COMT). COMT methylates DA's catechol structure to the metabolite, 3-methoxytyramine (3-MT). This methylation effectively prevents DA from activating its receptors. COMT has both soluble and membrane forms; the membrane-bound form has a higher affinity for DA and comprises the majority of brain COMT. Unlike DAT, membranebound COMT is not expressed in DA neurons, but rather by postsynaptic neurons and/or surrounding glia (Gogos et al., 1998; Schott et al., 2010). Due to its expression pattern, COMT plays an important role in degrading DA both within and outside of the synaptic cleft.

The olfactory bulb (OB) has a high number of DAergic short axon cells (SACs; Parrish-Aungst et al., 2007). SACs, along with GABAergic periglomerular cells and glutamatergic external tufted cells (ETCs), surround the glomeruli, the first circuit to process olfactory nerve sensory signals. The SACs co-release GABA and DA (Liu et al., 2013), and form an extensive network linking up to hundreds of glomeruli (Aungst et al., 2003; Kiyokage et al., 2010). SAC release of GABA causes inhibition of ETCs, which is followed by DA-D1 receptor-mediated rebound excitation. DA also activates D2 receptors located on olfactory nerve $(\mathrm{ON})$ terminals to cause presynaptic inhibition. As there are few anatomical synapses targeting $\mathrm{ON}$ terminals, DA's presynaptic action may be due to extra synaptic release or spread.

DA clearance within glomeruli is poorly understood. It could be metabolized by either MAO, COMT, or both: MAO converts DA to DOPAC and COMT converts DOPAC to homovanillic acid (HVA). The ratio of DOPAC to HVA indicates the proportion of DA processed by MAO versus COMT degradation. DOPAC/HVA ratios differ markedly in striatum versus $\mathrm{OB}$ (ElEtri et al., 1992). In striatum, the ratio of HVA to DOPAC is 0.85 suggesting a high efficiency DAT-MAO pathway, whereas in $\mathrm{OB}$ the ratio is 2.18 implying that COMT degradation predominates in glomerular circuits (El-Etri et al., 1992).

To investigate the prediction that COMT is the primary form of DA degradation in $\mathrm{OB}$, we measured COMT protein expression in $\mathrm{OB}$ and striatum by Western blot and immunohistochemistry. The results showed abundant COMT expression in $\mathrm{OB}$ compared with striatum. Moreover, DA levels measured by fast-scan cyclic voltammetry were dramatically elevated when $O B$ slices were treated with the COMT inhibitor, tolcapone. Together, these results show a prominent role for DA clearance by the COMT pathway in $\mathrm{OB}$ compared with striatum.

\section{Materials and Methods}

Mice. Adult male (6-8 weeks, C57BL6) wild-type and mice expressing cre recombinase under control of the tyrosine hydroxylase enzyme [B6.Cg$\mathrm{Tg}(\mathrm{Th}$-cre $) 1 \mathrm{Tmd} / \mathrm{J}]$ were purchased from the Jackson Laboratories. Additional lines of mice used in the analysis of COMT between strains were acquired from Jackson Laboratories [B6CBAF1/J strain, C57BL/6x129 strain cross, OMP synaptofluorin transgenic, Charles River Laboratories (CD1 strain) or courtesy of Dr Gabor Szabo (glutamic acid decarboxylase 65-gfp transgenic, Institute of Experimental Medicine, Hungary); at least $n=3$ of each strain]. Experimental procedures were performed in accordance with the University of Maryland Institutional Animal Care and Use Committee and National Institutes of Health guidelines.

Nares occlusion. Mice used in the nares occlusion part of the study $(n=$ 6 C57BL/6) were anesthetized by intraperitoneal injection of Nembutal
(50 mg/kg body weight). Unilateral nares occlusion of each mouse was performed with thermocautery of the nasal opening. After occlusion, mice were monitored and kept warm until full recovery. Mice were euthanized 7 or $14 \mathrm{~d}$ post-lesion and tissue was processed as described below for protein analysis.

Immunohistochemistry. Mice were anesthetized by intraperitoneal injection of ketamine/xylazine (ketamine $100 \mathrm{mg} / \mathrm{kg}$ and xylazine $10 \mathrm{mg} / \mathrm{kg}$ body weight in $0.9 \%$ saline solution), and then transcardially perfused with $0.9 \%$ saline followed by $4 \%$ paraformaldehyde (PFA) in phosphate buffer. Brains were postfixed in $4 \%$ PFA overnight at $4^{\circ} \mathrm{C}$. Brains were embedded in $10 \%$ gelatin, frozen in optimal cutting temperature compound (Sakura Finetek), and $25 \mu \mathrm{m}$ coronal sections cut on a Leica CM3050S cryostat.

For staining, free-floating sections were sequentially incubated in $1 \%$ bovine serum albumin (BSA) and $0.9 \%$ hydrogen peroxide in TBST $(0.1$ M Tris, $\mathrm{pH} 7.4,0.9 \%$ saline, $0.3 \%$ Triton $\mathrm{X}-100$ ) for $30 \mathrm{~min}$, then in primary antibody against COMT (BD Transduction Laboratories, Cata$\log \# 611970 ; 1: 50,000)$ or DAT (Millipore, Catalog \#MAB369; 1:1000) diluted in BSA-TBST was added for $48 \mathrm{~h}$. After this, sections were washed in TBST $(3 \times 5 \mathrm{~min})$, incubated in the respective biotin-conjugated donkey anti-mouse or anti-rat secondary antibodies (Jackson Immuno Research; $1: 500)$ for $1 \mathrm{~h}$ at room temperature, washed in TBST $(3 \times 5$ min), an avidin-biotin-HRP-conjugated complex (ABC kit; Vector Laboratories) in TBS, washed in TBS $(3 \times 5 \mathrm{~min})$, reacted with nickelintensified diaminobenzidine and finally washed in TBS $(3 \times 5 \mathrm{~min})$. Stained sections were dehydrated and coverslipped in DPX. Control reactions where one or both primary antibodies were omitted showed no significant staining. Digital microscopy images were captured with a Leica DMR microscope, and a Retigna Exi Fast 1394 camera (QImaging). Images were brightness, color, and contrast balanced then assembled into panels using CorelDraw Graphics Suite 15 (Corel).

Protein isolation and analysis. Mice were anesthetized by intraperitoneal injections of ketamine/xylazine and the main olfactory bulbs (MOBs) or striatum (STR) rapidly dissected out into ice-cold RIPA buffer (Teknova) with 10 mm PMSF (Fluka) and Complete Protease Inhibitor Cocktail (Roche). Fresh $500 \mu \mathrm{m}$ sections were made using a vibratome and microdissections of individual MOB layers performed as previously described (Bovolin et al., 2009; Hsieh and Puche, 2015). Briefly, under a high-magnification surgical dissecting microscope bulb layers were isolated: olfactory nerve fiber layer $(\mathrm{ONL})$, glomerular layer (GL), external plexiform layer (EPL), mitral cell layer (MCL), and granule cell layer (GCL). After dissection, all protein samples were homogenized in ice-cold dissection buffer and the protein concentration of each homogenate determined with a Bradford protein analysis kit (Bio-Rad).

SDS-PAGE was run with lanes containing either 10 or $100 \mu \mathrm{g}$ of each sample with ReadyPrep Rehydration/Sample buffer (Bio-Rad) on 12\% Mini-PROTEAN TGX gels (Bio-Rad). Proteins were transferred to PDVF membrane (Bio-Rad) for $1 \mathrm{~h}$ at $100 \mathrm{~V}$ in a Mini PROTEAN 3 Cell transfer tank (Bio-Rad). The membrane was blocked for 30 min with $5 \%$ nonfat dry milk in buffer containing $1 \mathrm{~m}$ Tris-buffered saline and $0.05 \%$ Tween and probed with antibodies in block solution against COMT (BD Transduction Laboratories, Catalog \#611970; 1:1000), DAT (Millipore, Catalog \#MAB369; 1:5000), tyrosine hydroxylase (TH; ImmunoStar, Catalog \#22941; 1:5000) or actin (Millipore Catalog \#MAB1501; 1:1000) at $4^{\circ} \mathrm{C}$ overnight. After rinses in TBST $(5 \times 5 \mathrm{~min})$, the membranes were incubated for $1 \mathrm{~h}$ at room temperature in goat anti-mouse or anti-rat peroxidase-conjugated secondary antibodies as appropriate for each primary (Jackson ImmunoResearch; 1:5000). After rinses in TBST $(5 \times 5$ $\mathrm{min}$ ), enhanced chemiluminescence (PerkinElmer) was applied to the blot, and then exposed to film (Denville Scientific). Nonsaturating exposures were developed and the resulting films digitized on a ChemiDoc MP Imaging System (Bio-Rad). ImageJ software (National Institutes of Health) was used to calculate the integrated optical density of each band, normalized to total protein or actin. The ratio of COMT to DAT was estimated by determining the relative optical intensity per microgram of protein in the ChemiDoc imaging system from each animal.

In vitro fast-scan cyclic voltammetry. Adeno-associated virus serotype 9 (AAV2.9) carrying fusion genes for channelrhodopsin (ChR2) and enhanced yellow (EYFP) fluorescent protein or mCherry (University of 


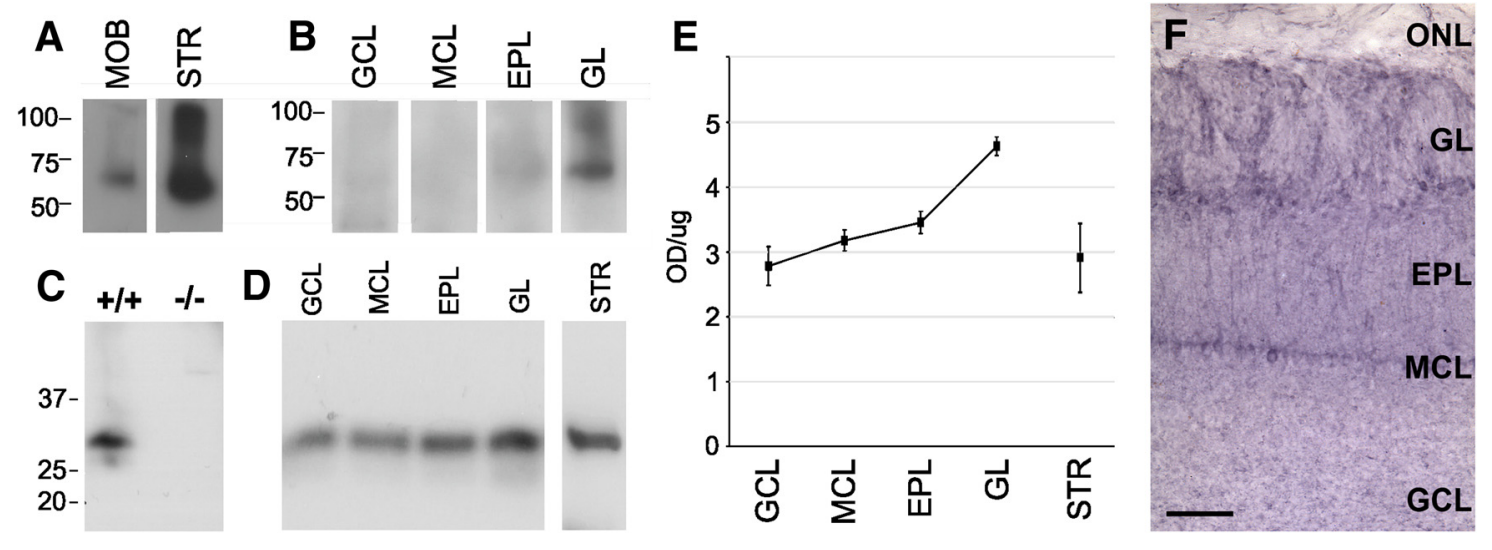

Figure 1. COMT expression. A, SDS-PAGE blot of DAT in the MOB (100 $\mu \mathrm{g}$ in lane) and STR (10 $\mu \mathrm{g}$ in lane) showing the expected molecular weight for DAT. $\boldsymbol{B}$, Micro-isolated layers of the OB stained for DAT showing the highest DAT expression in the GL, with little expression in the EPL and none in the deeper MCL and GCL. C, Expression of COMT in wild-type $\left(^{+/+}\right)$and null mutant $\left({ }^{-/-}\right)$. $D$, Micro-isolated layers of the $\mathrm{OB}$ and whole STR stained for COMT showing the highest intensity in the glomerular layer, but also expression in all deeper layers. $E$, Quantification of the relative abundance of COMT in layers of the olfactory bulb and striatum [relative optical density (OD) $\mathrm{U} / \mu \mathrm{g}$ total protein]. $\boldsymbol{F}$, Immunohistochemistry for COMT in the 0B. As expected from Western blot data, expression is present throughout the $\mathrm{OB}$ with the exception of the $\mathrm{ONL}$, which is devoid of significant staining. Scale bar, $80 \mu \mathrm{m}$.

Pennsylvania Vector Core) were injected into the glomerular layer of the medial OB in adult (6-week-old) TH-Cre mice. Under deep anesthesia, skull was exposed and a small hole was drilled over each OB with typical coordinates at $3.95 \mathrm{~mm}$ from bregma and $0.2 \mathrm{~mm}$ from midline. AAV2.9 was injected into three points of each bulb (depth $2.0 \mathrm{~mm}, 1.5$ and 1.0 $\mathrm{mm}$ ) at a rate of $0.1 \mu \mathrm{l} / \mathrm{min}$ for $5 \mathrm{~min}$. After 2-3 weeks for ChR2-EYFP fluorescent protein expression, acute $\mathrm{OB}$ slices were prepared for experiments.

Fresh slices of olfactory bulb from adult mice were prepared as previously described (Liu and Shipley, 2008). Briefly, horizontal slices (350 $\mu \mathrm{m})$ were cut with a VT1200s vibratome (Nussloch) in an ice-cold and oxygenated $\left(95 \% \mathrm{O}_{2}-5 \% \mathrm{CO}_{2}\right)$ sucrose-based artificial CSF (sucroseACSF) containing the following (in $\mathrm{mm}$ ): 204.5 sucrose, $3 \mathrm{KCl}, 1.25$ $\mathrm{NaH}_{2} \mathrm{PO}_{4}, 2.6 \mathrm{MgSO}_{4} 0.5, \mathrm{CaCl}_{2}, 26 \mathrm{NaHCO}_{3}$, and 10 glucose. After 30 min incubation in normal ACSF at $30^{\circ} \mathrm{C}$, slices were then transferred to ACSF at room temperature until they were used for experiments. Normal ACSF was continuously bubbled with $95 \% \mathrm{O}_{2}-5 \% \mathrm{CO}_{2}$ and had the following composition (in mM): $124 \mathrm{NaCl}, 3 \mathrm{KCl}, 1.25 \mathrm{NaH}_{2} \mathrm{PO}_{4}, 1.3$ $\mathrm{MgSO}_{4} 1.3 \mathrm{CaCl}_{2}, 26 \mathrm{NaHCO}_{3}, 10$ glucose, and 0.4 ascorbic acid. During experiments, slices were perfused at $3 \mathrm{ml} / \mathrm{min}$ with ACSF equilibrated with $95 \% \mathrm{O}_{2}-5 \% \mathrm{CO}_{2}$, warmed to $30^{\circ} \mathrm{C}$, and exposed to the COMT blocker tolcapone $(10 \mu \mathrm{m})$ or DAT blocker GBR12909 $(5 \mu \mathrm{m})$ as described in the results.

Fast-scan cyclic voltammetry signals were measured from the glomerular layer with carbon fiber microelectrodes produced from carbon fiber T650 (Amoco) fitted into $1.2 \mathrm{~mm}$ glass microcapillary tubes (A-M systems). Microelectrodes were cut at $75-100 \mu \mathrm{m}$ at the glass tip. Cyclic voltammograms were collected at $10 \mathrm{~Hz}$ by ramping up from -0.4 to $+1.3 \mathrm{~V}$ and back in a triangular fashion at $400 \mathrm{~V} / \mathrm{s}$. Data collection, stimulation timing and voltage application were controlled by interface boards and custom-written LabView routines (National Instruments; Cheer et al., 2004). Optical stimulation of ChR2 labeled TH neurons were delivered from a $25 \mu \mathrm{m}$ multimode optical fiber $\left(0.1 \mathrm{NA}, \sim 7^{\circ}\right.$ beam spread; ThorLabs) coupled to a $150 \mathrm{~mW}, 473 \mathrm{~nm}$, diode-pumped, solidstate laser (LWBL473083272, Laswerwave) gated with a Uniblitz shutter (Liu et al., 2013). Optical power at the fiber tip was calibrated with a PM20A power meter (ThorLabs). Onset and duration of optical stimulation was measured during every experiment by splitting $1 \%$ of the laser beam out to a high-speed (30 ns rise-time) silicon photosensor (model 818-BB, Newport).

\section{Results}

Dopamine transporter expression in the $\mathrm{OB}$

The DAT is the primary mechanism of DA clearance in the STR. Accordingly, DAT is a major target of many pharmacologic therapies, as well of drugs of abuse like cocaine. As expected, SDS-
PAGE of $10 \mu \mathrm{g}$ STR protein gave robust signal in a $70-85 \mathrm{kDa}$ band corresponding to the well characterized DAT molecular weight. Despite robust mRNA expression and DAT gene promoter activity in the OB (Zhou et al., 2009), previous studies reported the absence of DAT protein (Mitsumoto et al., 2005). When probed for DAT protein, a detectable SDS-PAGE signal was present only when 10 -fold more protein than for striatum was used (100 $\mu \mathrm{g} /$ lane OB, $10 \mu \mathrm{g} / \mathrm{lane}$ STR; Fig. $1 A)$. This indicates that the $\mathrm{OB}$ has $<10 \%$ DAT protein/weight tissue than STR.

DA neurons are restricted to the glomerular layer in the OB. Thus in whole bulb extracts the volume of tissue from deeper layers might dilute glomerular layer DAT protein estimates. To assess this we microdissected tissue (Bovolin et al., 2009) to isolate proteins separately from the GL, EPL, MCL, and the GCL. Layer extracts were run by SDS-PAGE and probed with DAT antibodies. A DAT band was detected only when using a high protein load $(100 \mu \mathrm{g})$ from each layer. As expected, the majority of the DAT protein was detected in the GL (Fig. 1B); lower expression was present in the EPL samples; this may reflect dissection contamination from the GL/EPL or scattered DA neurons at the GL/EPL boundary. These low levels of DAT protein expression in the MOB could not be detected by immunohistochemistry (IHC) on MOB sections. In contrast, as expected, striatum sections had robust IHC staining for DAT (data not shown). Together, these data indicate that, whereas DAT promoter/ mRNA is present DAT protein is negligible in OB neurons. This is consistent with the low levels of DOPAC in OB (El-Etri et al., 1992).

\section{COMT enzyme expression in the OB}

The low level of DAT coupled with the low level of DAT-MAO metabolic products, suggests that COMT catalysis is the predominant DA clearance mechanism in the OB. To measure OB COMT we used an antibody that recognizes the $28 \mathrm{kDa}$ membrane-bound form of the enzyme. To validate the selectivity and specificity of the antibody, we probed protein isolated from a COMT-null mutant mouse $\left(\mathrm{COMT}^{-1-}\right)$. In brain tissue isolated from these $\mathrm{COMT}^{-1-}$ mice there was no detectable signal compared with wild-type (Fig. 1C).

When microdissected OB layers were run by SDS-PAGE and probed for COMT, bands were detectable in all layers consistent with broader metabolic roles for COMT in cells not involved with DA metabolism. However, COMT expression levels were $\sim 50 \%$ higher in the GL than any other OB layers or the striatum $(n=5$ 


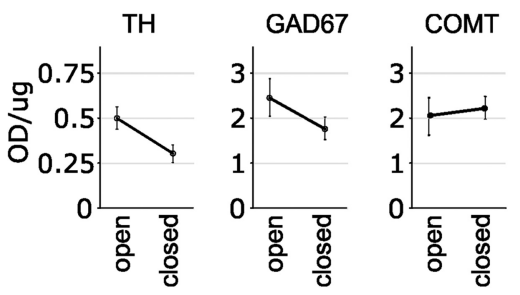

Figure 2. Quantification of TH, glutamic acid decarboxylase 65 kDa (GAD65), and COMT expression in a nares occlusion model [relative optical density (OD) $\mathrm{U} / \mu \mathrm{g}$ total protein]. Expression of TH and GAD65 are reduced $30-40 \%$ in the $0 B$ on the side of the closed nares, reflecting activity dependence of these proteins. COMT expression is identical in open and closed nares.

animals; Fig. $1 D, E)$. Immunohistochemistry for COMT showed staining on cell bodies and processes in all OB layers (Fig. $1 F$ ), consistent with the broad expression seen with SDS-PAGE. From our protein measurements, we estimate a stoichiometric COMT-DAT ratio of 30:1 in the bulb compared with $0.5: 1$ in the striatum. Thus, COMT expression is relatively high and DAT expression very low in OB glomeruli. In contrast, the striatum has low COMT expression and high DAT expression. These results indicate that DA clearance in OB is predominantly via COMT.

A hallmark feature of OB SACs is their strong dependence on neural activity for expression of the DA synthetic enzyme, TH (Baker et al., 1983, 1984) and the GABA synthetic enzyme glutamic acid decarboxylase-67 (GAD67; Parrish-Aungst et al., 2011). Reduced neuronal activity by nares closure or destruction of sensory neurons in the olfactory epithelium causes significant reductions of TH and GAD67 protein expression. To determine whether the COMT DA clearance mechanism is also regulated by neural activity, we measured OB COMT protein in mice in which one naris had been occluded for 2 weeks. Naris occlusion reduced TH and GAD67 to $\sim 71 \pm 14 \%$ and $57 \pm 9 \%$ of control values, respectively ( $p<0.05 ; n=6$; Fig. 2 ), consistent with previous reports (Baker et al., 1983, 1984; Parrish-Aungst et al., 2011). However, COMT levels were unaffected by nares occlusion (Fig. 2), indicating that COMT expression is independent of sensory neural activity.

An underappreciated phenotype of the MOB dopaminergic system is that there are marked differences TH levels in different mouse strains (F.L. Margolis, unpublished observations). To see whether this correlated with differences in the expression of $\mathrm{TH}$, the rate-limiting enzyme for $\mathrm{DA}$, we measured $\mathrm{TH}$ in several lines of mice. Indeed, $\mathrm{TH}$ abundance varied considerably among strains ( $n=3$ per strain; Fig. 3A). The GAD65gfp line expresses the highest $\mathrm{TH}$ and the $\mathrm{SpH} / 6 \mathrm{~T}$ line the least. COMT abundance also varied between the seven mouse strains ( $n=3$ per strain; Fig. $3 A$ ) with the lowest COMT abundance in the GAD65gfp line of mice. For the seven strains examined, those with higher COMT levels had lower TH levels (regression analysis: $R^{2}=0.6122$; Fig. 3B).

\section{Dopamine transients and clearance in the $\mathrm{OB}$}

SACs co-release DA and GABA in glomeruli acting on olfactory nerve (sensory) terminals (Wachowiak and Cohen, 1999; Berkowicz and Trombley, 2000; Ennis et al., 2001; McGann et al., 2005), ETCs (Liu et al., 2013), and possibly other glomerular neurons. To investigate the functional role of COMT at glomerular DA synapses, we measured changes in extracellular subsecond DA release with fast-scan cyclic voltammetry (FSCV) during activation of SACs in MOB slices. To selectively activate DAergic SACs, we expressed ChR2 using a cre-inducible AAV2.9 vector
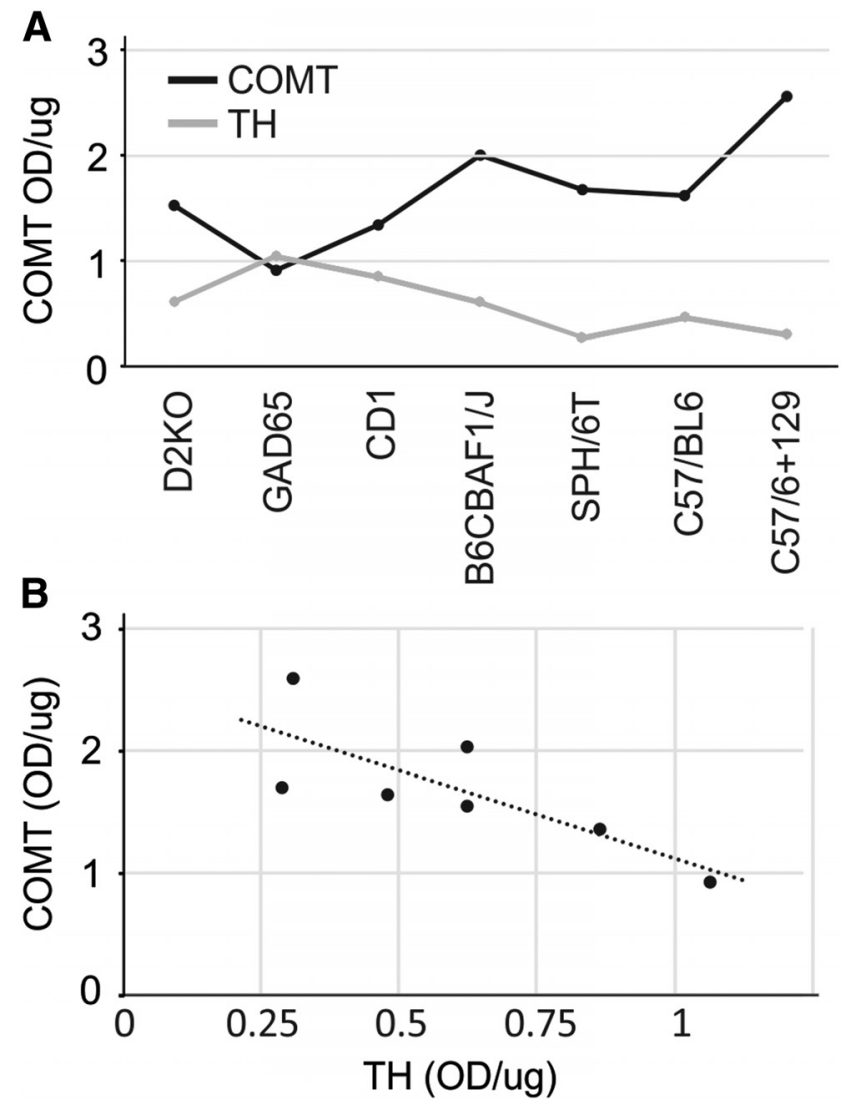

Figure 3. Comparison of COMT and TH expression in different strains/transgenic mice [relative optical density (OD) $\mathrm{U} / \mu \mathrm{g}$ total protein]. $A$, Expression levels of COMT (black line) and TH (gray line) between lines of mice varied as much as $2.5 \times$. B, Regression of relative COMT (ordinate) and TH (abscissa) between lines of mice.

carrying an inverted double-floxed ChR2-EYFP fusion construct microinjected into the glomerular layer of TH-cre mice (Liu et al., 2013). A carbon fiber electrode was inserted $\sim 100-150 \mu \mathrm{m}$ into the glomerular layer and ramp voltages cycling from -0.4 to $+1.3 \mathrm{~V}$ and back at $400 \mathrm{~V} / \mathrm{s}$ were applied to detect DA. In control conditions, optical stimulation of SACs reliably evoked DA release in neighboring glomeruli $(n=5$; Fig. $4 A)$, that exhibited the typical cyclic voltammogram signature characteristics of DA (Cheer et al., 2004). Based on the strong expression of COMT within the glomerular layer, we hypothesized that agents that reduce COMT activity should enhance FSCV DA signals. Indeed, bath application of the COMT inhibitor, tolcapone, increased FSCV DA signals $\sim 2$-fold ( $88 \pm 23 \%$ increase; $n=5$; $p<0.02$; Fig. 4). However, when the same comparison was performed with slices exposed to the DAT inhibitor GBR12909 there was no difference in FSCV signals (not significant; $n=6$; Fig. 4). Thus, we conclude that optically evoked release of DA is cleared primarily by COMT enzymatic degradation, and when COMT is inhibited, extracellular DA increases.

In summary, the high HVA-DOPAC ratio (El-Etri et al., 1992), the high levels of COMT protein expression coupled with low levels of DAT in OB and potentiation of vesicular release of DA by tolcapone inhibition of COMT together with the absence of modulation with DAT inhibition, all support the idea that COMT plays a major role in clearing DA at mouse OB dopaminergic synapses. 
A

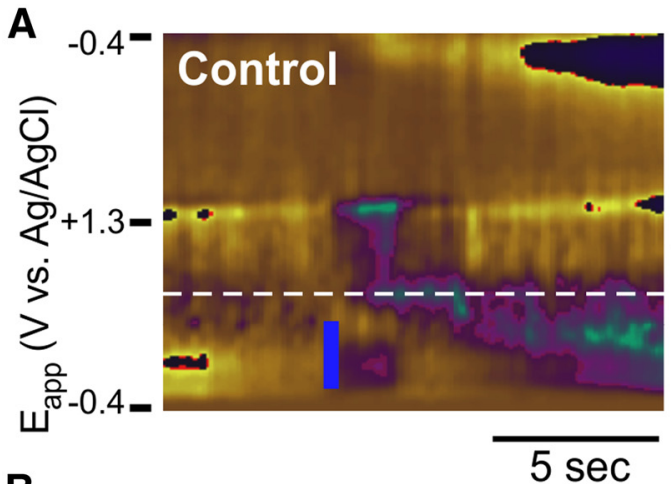

B

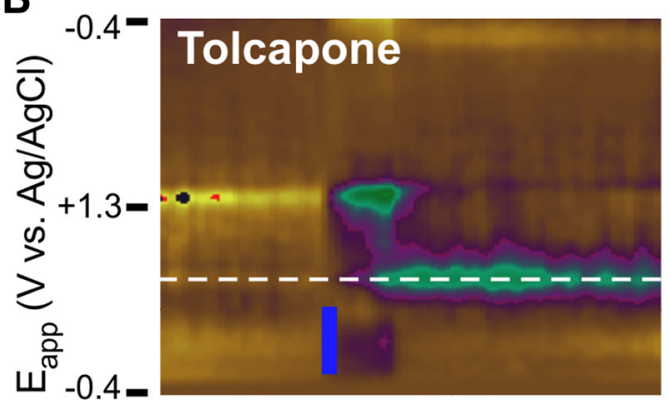

E

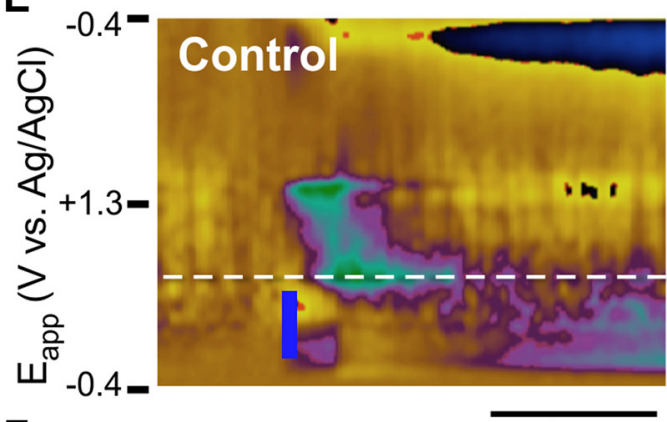

$\mathbf{F}$

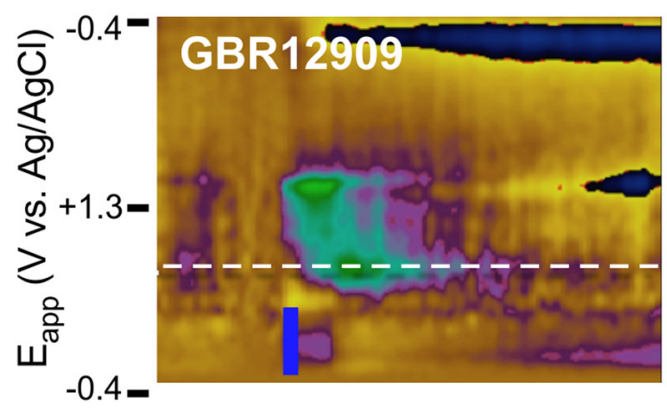

C

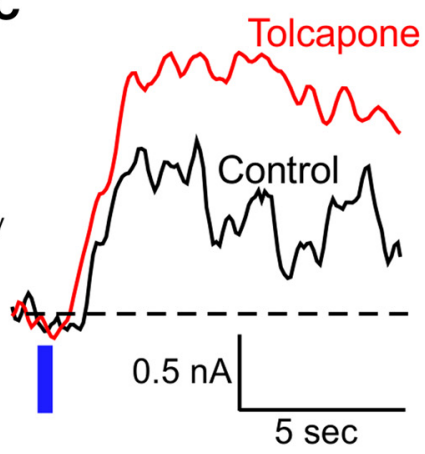

$0.0 \mathrm{nA}$

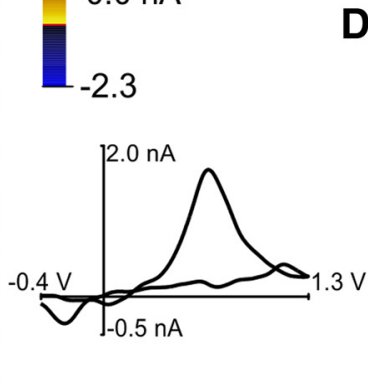

D

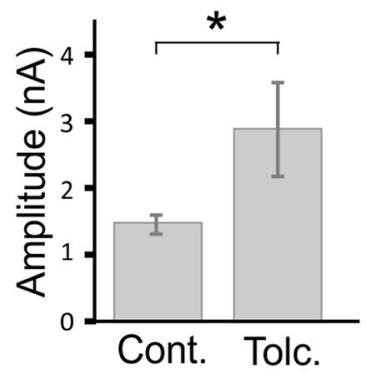

G

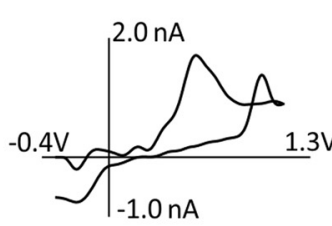

3.0

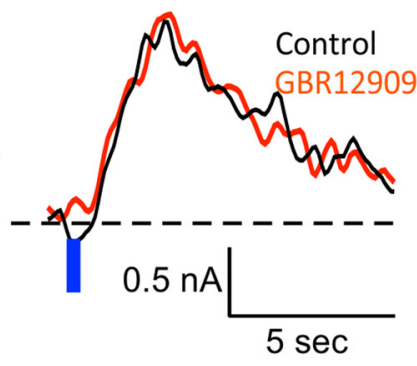

H

$-0.0 \mathrm{nA}$
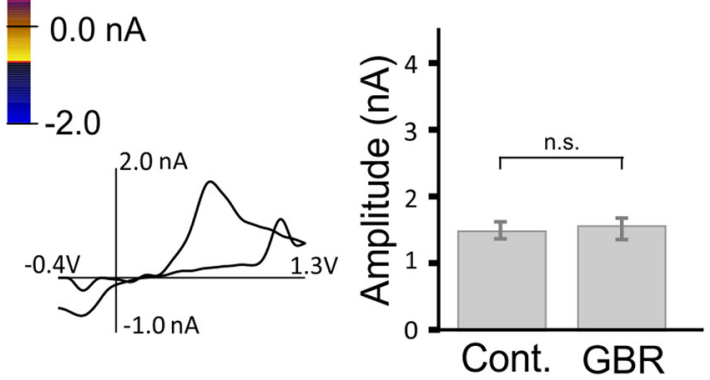

Figure 4. In vitro FSCV of DA release and metabolism in OB slices. $A, \mathrm{FSCV}$ detection of DA release evoked by optical stimulation (blue bar) of ChR2-expressing SACs. Plot shows current in pseudo-color versus applied potential (ordinate) and time (abscissa). Oxidative DA current in green. Inset, The voltammogram at the DA voltage potential. $\boldsymbol{B}$, The COMT inhibitor, tolcapone $(10 \mu \mathrm{M})$, increases DA signal. C, FSCV DA oxidation current from $(\boldsymbol{A})$ control and from $(\boldsymbol{B})$ tolcapone. $\boldsymbol{D}$, Average graph of the peak DA oxidative current in control conditions and in the presence of tolcapone. $\boldsymbol{E}$, FSCV detection of DA release evoked by optical stimulation (blue bar) of ChR2-expressing SACs. $\boldsymbol{F}$, The DAT inhibitor, GBR12909 (5 $\mu \mathrm{M}$ ), does not alter the DA signal. G, FSCV DA oxidation current from $(\boldsymbol{A})$ control and from $(\boldsymbol{B})$ GBR12909. $\boldsymbol{H}$, Average graph of the peak DA oxidative current in control conditions and in the presence of GBR12909.

\section{Discussion}

The brain has multiple populations of DA neurons. There are more DAergic neurons in main $\mathrm{OB}$ glomeruli than in the more extensively studied substantia nigra-ventral tegmental areas that target the striatum and nucleus accumbens (Guyenet and Crane, 1981; McLean and Shipley, 1988).
Synaptically released DA can be cleared by reuptake via DAT. DA re-enters the presynaptic terminal where it can be recycled or catabolized by the enzyme, MAO to DOPAC. Alternatively, synaptically released DA can be catabolized to HVA by the extracellular enzyme, COMT. The ratio of DOPAC to HVA provides an estimate of the proportion of DA processed by MAO versus 
COMT. The ratios of these metabolites differ markedly in STR and OB (El-Etri et al., 1992). In striatum, the ratio of HVA to DOPAC is 0.85 , consistent with a high efficiency DAT-MAO pathway. In contrast, in OB the HVA to DOPAC ratio is 2.18, suggesting that COMT degradation might predominate (El-Etri et al., 1992). The present biochemical and immunohistochemical results showing that $\mathrm{OB}$ has strong COMT expression and relatively low expression of DAT compared with striatum are entirely consistent with this inference. Indeed, the results underscore that two neural systems using the same neurotransmitter may differ markedly at the biochemical level, and thus cautions against extrapolation by analogy or to assume that a drug's action on one system will act the same way in another.

DAT regulates the extracellular concentration of DA and its recycling into presynaptic terminals (Torres, 2006). It has a high affinity for DA and is the primary mechanism for DA clearance in many areas with abundant DA synapses, such as the striatum. OB glomeruli also contain abundant DA synapses. However, the present results show that DAT protein levels are very low in OB, requiring $10 \times$ the amount of tissue as striatum to obtain detectible signals. This low abundance of DAT protein is consistent with the study of Mitsumoto et al. (2005), reporting complete absence of DAT protein in OB. They also observed reduced toxicity with methyl-4-phenyl-1,2,3,6-tetrahydropyridine (MPTP), as the MPTP toxin requires DAT to transport the toxin into cells (Mitsumoto et al., 2005). Our detection of very low DAT protein versus none reported by Mitsumoto et al. (2005) may be due to improved sensitivity of our chemiluminescent method. The paucity of cocaine action and no detection of DAT by photo-affinity labeling of the transporter (Lew et al., 1991) also indicate low levels of physiologically significant DAT in mouse. However, there may be species variation as detectable DAT is present in the rat OB (Freed et al., 1995).

The finding of low levels of DAT protein expression in $\mathrm{OB}$ contrasts with a DATgfp knock-in that displays robust GFPpositive neurons in OB (Zhou et al., 2009) and in situ hybridization data showing DAT in the MOB (Fujita et al., 1993; Shimada et al., 1998). However, the DATgfp model assesses DAT promoter activity, and in situ hybridization shows only the presence of mRNA. Our measure of protein levels indicates that, although DAT promoter and mRNA are present, only limited amounts of protein are translated. The mismatch between promoter activity/ mRNA levels and transcribed protein can occur for other genes and cell types. Indeed, in the bulb many neurons in deeper $\mathrm{OB}$ layers have TH promoter activity (Saino-Saito et al., 2004) and mRNA expression but no protein translation (Baker et al., 1983). The functional significance of regulating DAT and $\mathrm{TH}$ at the translational but not the transcriptional level is unclear.

Mechanisms of DA clearance differ in different brain areas. In a DAT knock-out mouse, DA persists much longer at the synapse in striatum but is cleared efficiently in prefrontal cortex (PFC). By contrast, inhibiting or genetically deleting COMT significantly elevates DA (Gogos et al., 1998) in PFC but not in striatum. Together with the present findings, these support the conclusion that COMT catabolism is the predominant mode of DA clearance in OB glomeruli and the PFC.

\section{DA actions in the $\mathrm{OB}$}

DA attenuates glutamate release from the ON by activation of presynaptic D2 receptors on ON axon terminals (Wachowiak and Cohen, 1999; Berkowicz and Trombley, 2000; Ennis et al., 2001; McGann et al., 2005). This action can be demonstrated functionally, despite the absence of anatomically distinct DA syn- apses onto ON terminals in electron microscope images. This had led to the idea that DA diffuses from SAC presynaptic release sites to the ON terminals resulting in functionally relevant levels of extra-synaptic of DA. Indeed, blocking DA- $\mathrm{D}_{2}$ receptors causes a $\sim 30 \%$ increase in OSN presynaptic calcium signals (Wachowiak and Cohen, 1999) and glomerular postsynaptic responses (Berkowicz and Trombley, 2000; Ennis et al., 2001; McGann et al., 2005), supporting the idea that synaptic release from SACs generates functional DA "tone". In the PFC, where there is little DAT, ventral tegmental DAergic neuronal bursts release high levels of DA (Sesack and Grace, 2010), which is thought to diffuse from presynaptic release sites to nearby cells (Schott et al., 2010). It has been speculated that COMT and the norepinephrine transporter clear extra synaptic DA in this circuit (Schott et al., 2010). DA diffusion and COMT degradation in OB might similarly regulate DA actions at $\mathrm{DA}-\mathrm{D}_{2}$ receptors on OSN terminals. The activity dependence of $\mathrm{TH}$ expression in the $\mathrm{OB}$, coupled with activity independence of COMT, could result in a potent suppression of steady-state DA level by abundant COMT degradation. We speculate that tonic DA could be affected earlier than phasic DA release synaptically during periods of lowered olfactory input activity and lowered TH/DA, allowing for a wider dynamic range of phasic DA responses to occur. However, tonic DA release presynaptically inhibits olfactory nerve terminals. Reduced DA levels with unaltered COMT should reduce this presynaptic inhibition and increase sensory input strength. Thus, there may be reduced excitation in one glomerular circuit and reduced presynaptic inhibition of inputs to this circuit.

Our current knowledge of the interglomerular circuit indicates that DA is co-released with GABA at SAC $\rightarrow$ ETC synapse. GABA release triggers fast $\mathrm{GABA}_{\mathrm{A}}$ receptor-mediated hyperpolarization and inhibits ETC spiking; DA release, on the other hand, engages a strong $l$ h current that enhances rebound excitation (Liu et al., 2013). The net result is an inhibition-excitation sequence in ETCs that temporally gates sensory signals in the glomerular circuit. The amount of DA measured at SAC synapses was doubled when COMT was inhibited by tolcapone. Thus, by regulating the ratio of GABA versus DA action on ETCs, COMT may significantly influence glomerular sensory signal processing.

\section{References}

Aungst JL, Heyward PM, Puche AC, Karnup SV, Hayar A, Szabo G, Shipley MT (2003) Centre-surround inhibition among olfactory bulb glomeruli. Nature 426:623-629. CrossRef Medline

Baker H, Kawano T, Margolis FL, Joh TH (1983) Transneuronal regulation of tyrosine hydroxylase expression in olfactory bulb of mouse and rat. J Neurosci 3:69-78. Medline

Baker H, Kawano T, Albert V, Joh TH, Reis DJ, Margolis FL (1984) Olfactory bulb dopamine neurons survive deafferentation-induced loss of tyrosine hydroxylase. Neuroscience 11:605-615. CrossRef Medline

Berkowicz DA, Trombley PQ (2000) Dopaminergic modulation at the olfactory nerve synapse. Brain Res 855:90-99. CrossRef Medline

Bovolin P, Bovetti S, Fasolo A, Katarova Z, Szabo G, Shipley MT, Margolis FL, Puche AC (2009) Developmental regulation of metabotropic glutamate receptor 1 splice variants in olfactory bulb mitral cells. J Neurosci Res 87:369-379. CrossRef Medline

Cheer JF, Wassum KM, Heien ML, Phillips PE, Wightman RM (2004) Cannabinoids enhance subsecond dopamine release in the nucleus accumbens of awake rats. J Neurosci 24:4393-4400. CrossRef Medline

El-Etri MM, Nickell WT, Ennis M, Skau KA, Shipley MT (1992) Brain norepinephrine reductions in soman-intoxicated rats: association with convulsions and AChE inhibition, time course, and relation to other monoamines. Exp Neurol 118:153-163. CrossRef Medline

Ennis M, Zhou FM, Ciombor KJ, Aroniadou-Anderjaska V, Hayar A, Borrelli E, Zimmer LA, Margolis F, Shipley MT (2001) Dopamine D2 receptormediated presynaptic inhibition of olfactory nerve terminals. J Neurophysiol 86:2986-2997. Medline 
Freed C, Revay R, Vaughan RA, Kriek E, Grant S, Uhl GR, Kuhar MJ (1995) Dopamine transporter immunoreactivity in rat brain. J Comp Neurol 359:340-349. CrossRef Medline

Fujita M, Shimada S, Nishimura T, Uhl GR, Tohyama M (1993) Ontogeny of dopamine transporter mRNA expression in the rat brain. Brain Res Mol Brain Res 19:222-226. CrossRef Medline

Gogos JA, Morgan M, Luine V, Santha M, Ogawa S, Pfaff D, Karayiorgou M (1998) Catechol-O-methyltransferase-deficient mice exhibit sexually dimorphic changes in catecholamine levels and behavior. Proc Natl Acad Sci U S A 95:9991-9996. CrossRef Medline

Guyenet PG, Crane JK (1981) Non-dopaminergic nigrostriatal pathway. Brain Res 213:291-305. CrossRef Medline

Hersch SM, Yi H, Heilman CJ, Edwards RH, Levey AI (1997) Subcellular localization and molecular topology of the dopamine transporter in the striatum and substantia nigra. J Comp Neurol 388:211-227. CrossRef Medline

Hsieh YC, Puche AC (2015) GABA modulation of SVZ-derived progenitor ventral cell migration. Dev Neurobiol 75:791-804. CrossRef Medline

Kiyokage E, Pan YZ, Shao Z, Kobayashi K, Szabo G, Yanagawa Y, Obata K, Okano H, Toida K, Puche AC, Shipley MT (2010) Molecular identity of periglomerular and short axon cells. J Neurosci 30:1185-1196. CrossRef Medline

Lew R, Grigoriadis D, Wilson A, Boja JW, Simantov R, Kuhar MJ (1991) Dopamine transporter: deglycosylation with exo- and endoglycosidases. Brain Res 539:239-246. CrossRef Medline

Liu S, Shipley MT (2008) Multiple conductances cooperatively regulate spontaneous bursting in mouse olfactory bulb external tufted cells. J Neurosci 28:1625-1639. CrossRef Medline

Liu S, Plachez C, Shao Z, Puche A, Shipley MT (2013) Olfactory bulb short axon cell release of GABA and dopamine produces a temporally biphasic inhibition-excitation response in external tufted cells. J Neurosci 33: 2916-2926. CrossRef Medline

McGann JP, Pírez N, Gainey MA, Muratore C, Elias AS, Wachowiak M (2005) Odorant representations are modulated by intra- but not interglomerular presynaptic inhibition of olfactory sensory neurons. Neuron 48:1039-1053. CrossRef Medline
McLean JH, Shipley MT (1988) Postmitotic, postmigrational expression of tyrosine hydroxylase in olfactory bulb dopaminergic neurons. J Neurosci 8:3658-3669. Medline

Mitsumoto Y, Mori A, Ohashi S, Nakai M, Moriizumi T (2005) Differential effects of 1-methyl-4-phenyl-1,2,3,6-tetrahydropyridine in the olfactory bulb and the striatum in mice. Neurosci Res 51:111-115. CrossRef Medline

Parrish-Aungst S, Shipley MT, Erdelyi F, Szabo G, Puche AC (2007) Quantitative analysis of neuronal diversity in the mouse olfactory bulb. J Comp Neurol 501:825-836. CrossRef Medline

Parrish-Aungst S, Kiyokage E, Szabo G, Yanagawa Y, Shipley MT, Puche AC (2011) Sensory experience selectively regulates transmitter synthesis enzymes in interglomerular circuits. Brain Res 1382:70-76. CrossRef Medline

Saino-Saito S, Sasaki H, Volpe BT, Kobayashi K, Berlin R, Baker H (2004) Differentiation of the dopaminergic phenotype in the olfactory system of neonatal and adult mice. J Comp Neurol 479:389-398. CrossRef Medline

Schott BH, Frischknecht R, Debska-Vielhaber G, John N, Behnisch G, Düzel E, Gundelfinger ED, Seidenbecher CI (2010) Membrane-bound catechol-O-methyl transferase in cortical neurons and glial cells is intracellularly oriented. Front Psychiatry 1:142. CrossRef Medline

Sesack SR, Grace AA (2010) Cortico-basal ganglia reward network: microcircuitry. Neuropsychopharmacology 35:27-47. CrossRef Medline

Shimada A, Mason CA, Morrison ME (1998) TrkB signaling modulates spine density and morphology independent of dendrite structure in cultured neonatal Purkinje cells. J Neurosci 18:8559-8570. Medline

Torres GE (2006) The dopamine transporter proteome. J Neurochem 97: 3-10. CrossRef Medline

Wachowiak M, Cohen LB (1999) Presynaptic inhibition of primary olfactory afferents mediated by different mechanisms in lobster and turtle. J Neurosci 19:8808-8817. Medline

Zhou W, Lee YM, Guy VC, Freed CR (2009) Embryonic stem cells with GFP knocked into the dopamine transporter yield purified dopamine neurons in vitro and from knock-in mice. Stem Cells 27:2952-2961. CrossRef Medline 